\title{
TGFa-PE38 Immunotoxin
}

National Cancer Institute

\section{Source}

National Cancer Institute. T GFa-PE38 Immunotoxin. NCI Thesaurus. Code C29483.

A recombinant, chimeric toxin composed of human transforming growth factor alpha

(T GF-alpha) fused to a fragment of Pseudomonas exotoxin (PE38) without its cell-binding domain. The TGF-alpha moiety of the agent attaches to tumor cells expressing the epithelial growth factor receptor (EGFR); the exotoxin induces caspase-mediated apoptosis of tumor cells via a mechanism involving mitochondrial damage; it also catalyzes the transfer of ADP ribose from nicotinamide adenine dinucleotide (NAD) to elongation factor-2 in eukaryotic cells, thereby inactivating elongation factor 2 and inhibiting protein synthesis. ( $\mathrm{NCl04)}$ 